\title{
Mindful Adaptation of Technology (MAT) in Extreme Research Contexts: A Theoretical Proposal
}

\author{
Michael Matthews \\ The University of Oklahoma \\ michael.j.matthews-1@ou.edu
}

\author{
Heshan Sun \\ The University of Oklahoma \\ sunh@ou.edu
}

\begin{abstract}
With the advent of the COVID-19 pandemic, information system researchers have begun to explore ways in which information technology artifacts have meaning within the context of this seismic event. Within this manuscript, we develop a new concept, namely: mindful adaptation of technology (MAT), and subsequently derive a research model based on event systems theory, coping theory, and mindfulness research. We theoretically position this multi-faceted construct of MAT within existing models and demonstrate its novelty and utility for understanding technological adaptation in response to extreme research contexts. We conclude with theoretical implications and direction for future research.
\end{abstract}

\section{Introduction}

Since its genesis in late 2019 and early 2020, the COVID-19 pandemic placed many individuals in uncharted waters. Modern technology enabled many individuals and organizations to pivot in reaction to ever evolving social norms and eventual governmental restrictions during COVID-19: universities offered courses online, employers relaxed in-person requirements, and individuals creatively found ways to remotely keep in contact with loved ones. Illustratively, the search term "Zoom" on Google (which related terms suggest to primarily be a reference to the videoconferencing software) saw a large spike as the COVID19 pandemic emerge [1], as did the stock price and number of users [2]. Indeed, the titles of popular press articles testify to the impactful manner in which COVID-19 has shifted technology usage: "COVID-19: The Unexpected Catalyst For Tech Adoption" [3] and "Why COVID-19 Is Accelerating The Adoption Of AI And Research Tech" [4]. Correspondingly, we postulate that individuals' adaptation of technology usage during the COVID-19 pandemic is unprecedented in nature.

A substantial amount of technology advancement (and subsequent adoption and adaptation) is spawned from the occurrence of events. Lives are full of events that challenge the status quo so greatly that we start considering changing our behavior [5]. Events can range in their size, impact, and duration [6]; whereas many events can be relatively small and often remain unarticulated, history tells of more seismic events which can singularly influence the technology usage of an entire population and forever impact a generation. For example, the need to crack the German "enigma codes" fueled the advancement of electronic computers by Allied forces [7], and the tension of the Cold War stimulated the progress of RFID technology [8]. Similarly, the 2001 attacks on the World Trade Centers and Pentagon triggered the creation and widespread usage of the advanced Global Terrorism Database [9]. More recently - and especially salient for the current audience - the COVID-19 pandemic has also been a driving factor of technology adaptation.

The COVID-19 pandemic can be understood as both a novel and disrupting event. As Morgeson et al. aptly note, "when events are novel, entities are usually ill prepared with a set of rules or procedures to effectively respond to the events", and, "disruption to the ordinary and predictable flow of experience triggers further analysis...this requires more deliberate, effortful information processing and changes to existing behaviors and features or the creation of new behaviors, features, and events" [6:521]. Statements such as these underscore the existence of adaptation - such as technology adaptation - in the presence of novel and disrupting events such as COVID-19.

In addition to being a novel and disrupting event, COVID-19 can also be rightfully understood as an extreme research context (ERC). ERC as a topic of analysis has a rich history within organizational science [10]. Events that are largely disrupting are "frequently portrayed as unique, unprecedented or even uncategorizable" [11:846], and we believe that COVID19 fits this classification. In contrast to previous ERCs, no other event in history can quite compare to the collective and technology-driven response that was witnessed. However, as we seek to understand individuals' adaptation of technology usage in the face 
of ERCs, extant IS theory is relatively silent. In response to this theoretical void, we review relevant literature and then propose mindful adaptation of technology (MAT) as a multi-faceted reflective high-order factor. Specifically, we argue that technology adaptation in a mindful manner can help people cope with ERCs and bring better wellbeing to the user. Consistent with the existing mindfulness research [12-16], we introduce and elucidate four dimensions of MAT and provide COVID19 related examples. We subsequently demonstrate how this construct enriches existing coping and event systems theory to explain the reaction of individuals within ERCs. This research contributes to IS theory (via seven propositions) in several ways. First, we uniquely join event system and coping models to understand technology adaptation at individual level. Second, we enrich technology coping models by reemphasizing the role that event attributes (e.g., duration) have on coping appraisals and adaptation, especially in the presence of ERCs. Third, we present and contextualize a new construct of MAT. Lastly, our model gives preference to subjective wellbeing outcomes, which showcases the meaningful impact of MAT in the context of ERCs. This elevation of the outcomes of MAT is one of key contributions of our framework.

\section{Theoretical Framework}

While many theories can - and should - be used to understand ERCs, we select event systems and coping theory as theoretical lenses for understanding individual technology adaptation. To our knowledge, this manuscript represents the first introduction of event systems theory to the IS domain. First, event systems theory $[6,17]$ is especially appropriate as it reestablishes the profound role of events in triggering action. ERCsby definition - are situations in which unique external events overwhelm organizations (and individuals) and result in significant consequences on a physical, psychological or material level. To understand ERCs, a robust exploration of the role of event attributes is paramount.

Along parallel lines of logic, coping theory has a strong track record of predicting how individuals cope in the presence of technology-related phenomena [18]. Even if the "event" is not related to an IT-construct (e.g., the failure of a datacenter), the reach of ERCs is enough to penetrate the habits and routines of technology use. In response to an ERC, individuals may be forced to forfeit their usage of certain technologies, increasingly rely upon certain features, or completely adapt their usage. For example, an enormous spike in Google search terms demonstrates that after the referendum of BREXIT, Britain citizens stampeded to online sources as a part of an initial coping appraisal of the situation
[19]. Thus, we maintain that individuals will engage in technology-related coping mechanisms to handle the consequences of ERCs. As such, we now briefly review the core tenets of event system and coping theory to serve as a theoretical foundation of our model.

\subsection{Event Systems Theory}

Building off of open system theory [20] and previous systems research [21], event systems theory was originally promoted by Morgenson et al. $[6,17]$ and has since been used to bridge feature- and process-oriented research. Event systems theory is concerned with understanding the meaning of events on organizational and individual action. Those who subscribe to event systems theory evangelize three main constructs: event strength (e.g., novelty, disruption, criticality), event space (e.g., where an event occurs), and event time (e.g. event duration) [6]. However, the salience of these constructs varies across studies, and reasonable applications of event systems theory have excluded specific constructs [22-25]. Event systems is primarily organizationally focused, though it has been applied at an individual level as well [25]. However, event systems theory is specifically equipped to demonstrate how individuals react when rooted in collective action, especially when used conjointly with coping theory. In contrast to a personal traumatizing event (e.g., being in a major car accident), an ERC is communally understood (e.g., a town responding to a local flood). For COVID-19, an employee's response is significantly informed by the reactions of their supervisor, child's school board, governor, mayor, neighbors, and family. Thus, a theoretical lens that employs both event system theory (organizational-focus) and a coping model (individually-focused) to understand ERCs (which contains both communal and individual reactions that inform each other) is likely to flush out the unique way in which a person responds to an event in a shared context.

Previously, we introduced ERCs. Here, we demarcate that ERCs are one type of event [10]; however, ERCs are unique events in which the novelty and disruption are of such magnitude that they become a category within themselves. Hence, for our present purposes, we cite that the existence of an ERC already embeds important event systems constructs such as novelty and disruption; thus, we follow previous empirical work in solely emphasizing the constructs of event criticality, urgency, and duration [17].

Prior to fleshing out these constructs, it is worth noting that individuals can vary in their perception of an event; different individuals, in the same context, can interpret the same situation heterogeneously. In expounding upon how a situation is perceived, scholars note the difference 
between objective physical cues and subjective characteristics [26]. For example, the objective physical cues of a situation would include the elements that can be measured concretely: the presence of novel coronavirus, asymptomatic patients, coffins, etc. In contrast, the subjective characteristics of a situation are imbued with meaning by those living the event and is subjective to each individual. Thus, in relation to event criticality, urgency, and duration, perception serves an important role.

Event criticality is one of the components of event strength and refers to the level of importance of an event. "The more critical the event, the more likely it will be seen as a salient and require unusual attention" [6:521]. Previous work has asserted that events that are high in their level of criticality will frustrate efforts to maintain routines [17] and will prompt additional analyses [27]. If an event is perceived as critical, individuals and organizations are more prone to dedicate resources to address the situation at hand [28]. Conversely, an event that is low in perceived criticality may be placed on the resource-allocation backburner.

Naturally, ERCs are likely to be higher in criticality than the mundane events of the regular day-to-day. However, within the subject of ERCs, criticality can vary among ERC events. For example, the following ERCs are likely to represent a range of criticality: a chemical disaster [29], wildfires [30], a museum roof collapse [11], a school-related shooting [31], heatwaves [32], and a genocide [33]. Understanding event criticality must be firmly rooted in investigating those impacted - at least in some measure - by the event. An event (e.g., a drought in Afghanistan) is likely to be low in perceived criticality for a random person (e.g., someone living in Brazil). We do note that criticality can be perceived differently among individuals within a specific context. In the example of the ExxonMobil Valdez oil spill in 1989, native Alaskans (and their children), the corporate executives of ExxonMobil, and commercial fisherman all may have experienced the situation in various levels of criticality.

Event urgency refers to the level to which individuals or organizations must respond to an event in order to capitalize on the opportunities or to mitigate potential negative impacts [17]. The level of urgency can shape the way in which people behave in a specific context. For example, research has suggested that a team's progress at completing a task is motivated more by awareness of deadlines (i.e., urgency), than by completion of an absolute amount of work [34]. Leaders have also been shown to intentionally redirect attention towards resolving an urgent issue in a timesensitive manner [17]. In relation to ERCs, on the surface it may appear that there is little to no variance in event urgency: how does one not adopt a "drop everything else" mentality in the face of a police shooting or a nuclear power plant failure? However, upon closer examination it becomes clear that an event may ebb in perceived urgency.

Lastly, event duration is reflective of how long the event persists. Here, we suggest that ERCs are better understood as dynamic as opposed to static occurrences [35], in which the event and its consequences unfold over time. While a terrorist bombing is relatively a brief event, the development of the overall event experience is dynamic and is a conglomerate of multiple reactions and adaptations. In studying ERC, event duration is especially salient when triangulating with criticality and urgency. During the COVID-19 outbreak, the pandemic was perceived by some as both critical and urgent. However, as the event continues in duration, adaptation strategies are reevaluated due to sustainability complications. For example, President Trump emphasized that reopening the economy was essential citing that the then-current strategy could not be sustained for a prolonged period of time [36]. Morgenson et al. [6] posit that-holding event strength and event outcomes equal - that events that are longer in duration will more likely prompt adaptation.

\subsection{Coping Theory}

Coping theory was originally proposed by Lazarus and Folkman $[37,38]$ and has since been widely used within IS research to predict the behaviors of individuals and users in response to IT-related events. (For a review, see Weinert's [18] recent review on the subject within IS literature). In their seminal piece, Lazarus and Folkman define coping as, "the cognitive and behavioral efforts exerted to manage specific external and/or internal demands that are appraised as taxing or exceeding the resources of the person" [38:141]. Thus, coping can be thought of as the adjustments individuals undergo in response to a disruption in their environment. According to this model two main mechanisms are used by individuals to cope: appraisals and coping efforts. Below, we further expound on the axioms of coping theory to forecast how they are embedded in our research model.

When a user is first exposed to an event, they first analyze the potential consequences of an event - known as an appraisal within the coping literature. One of the key tenets of coping theory is a two-part appraisal process. During the primary appraisal, individuals will assess whether or not the event represents an opportunity, threat, or a combination of the two. As Lazarus and Folkman [38] note, events are multilayered and a singular event can contain both threats and opportunities. During the secondary appraisal, individuals assess how much control they have over 
their situation and how much they can avoid the situation at hand.

After the primary and secondary appraisals, individuals then undergo coping efforts, which can vary depending on the context. Within IS research, for example, Bhattacherjee and colleagues [39] found that various combinations of primary and secondary appraisals give rise to heterogenous responses-or coping efforts - and that those coping efforts can dynamically change as individuals cyclically undergo primary and secondary appraisals. Similarly, Bala and Venkatesh [40] posited four coping efforts that individuals activate after an IT implementation: exploration-to-innovate, exploitation, exploration-torevert, and avoidance. Understandably, each situation is likely to exhibit a range of potential coping efforts (e.g., venting, accepting, avoidance, task adaptation) [18]. Based upon coping efforts exerted by the individual, certain outcomes are anticipated to surface. Within the IS domain, the most commonly studied outcomes are job-related (e.g., performance, satisfaction) and ITrelated outcomes (e.g., software usage, integration, adoption) [18].

As noted, previous IS application of coping theory primarily explores IT-related events as the antecedents (e.g., internet security attacks, phishing emails, IT implementation, technostress creators), and principally focuses on job-level outcomes (e.g., job burnout, job performance, IT use, IT-work system integration, adaptation of anti-malware) [18]. However, to our knowledge, the IS conceptualization of the coping model has never been applied to constructs which umbrellas work-related events. In the face of an ERC, the appraisals, coping efforts, and outcomes related to digital technology are anticipated to be more pronounced than job-related operationalizations would be able to appreciate.

\section{Mindful Adaptation of Technology}

Originating from Buddhist practices [41], the concept of mindfulness has been applied to a variety of contexts, ranging from stress reduction [42] to business productivity [43]. Although definitions of mindfulness vary [13], mindfulness within academia is generally thought to be "a state of alertness and lively awareness, which is specifically manifested in typical ways" [15:138], with several other scholars adopting this definition [44-49]. Particularly within the IS domain, mindfulness has been explored in a variety of contexts [13, 50-54]. Although within IS literature mindfulness has generally been studied at the organizational or team level [44, 55-56], researchers have also successfully studied mindfulness at the individual level [13, 57]. Mindfulness is especially salient when discussing how individuals seek to adapt their behavior, as mindfulness can assist users to react to changing contexts to achieve better task technology fit [58]. In the context of reacting to ERCs, mindfulness can help individuals be more involved in the decision-making process. Prior research supports this assertion. For example, Langer [15, 59] maintains that when individuals feel a heightened state of involvement or presence in the moment, they are more likely to detect changes in their environment and subsequent opportunities for action.

Here we introduce a new concept: mindful adaptation of technology (MAT). In line with previous work [13, 60], we define MAT as a psychological state of consciousness in which a person focuses on and is aware of the issues related to a technology adaptation decision. MAT captures how individuals make technology adaptation decisions when they are alert to distinction, aware of multiple perspectives, open to novelty, and are firmly oriented in the present. Although mindfulness can be a trait variable, research has also explored mindfulness as a state variable $[13,15,44-45,60]$, and we employ the latter. Following closely to Sun, Fang, and Zou [13], we introduce mindful adaptation of technology as multi-faceted construct with four dimensions (Table 1). In the following sections, we elaborate on each of the four dimensions.

\subsection{Alertness to Technological Distinction}

One dimension of mindfulness is being sensitive to one's environment [14]. We operationalize this attribute within MAT by introducing the dimension of alertness to technological distinction. As events (both extreme and non-extreme) occur, individuals are presented with reason(s) to adapt their technology usage. Alertness of how the presence of an event shapes personal technology adaptation is an important indicator of how intentional the individual is being. A person who is unaware of how technology usage has changed in response to an event is unlikely to have been aware of their adaptation and reflects a level of insensitivity to their environment.

\subsection{Awareness of Multiple Technological Perspectives}

Another dimension of mindfulness is being aware of multiple perspectives [14]. Again, we apply this to element as one dimension of MAT. Mindful technology adaptation - as opposed to adaptation in generalimplies the existence and awareness of options. Simply making decisions based upon a singular paradigm is conceivably a product of compulsion, arrogance, or ignorance and may even exacerbate the problem. In 
order to engage in MAT, individuals consider alternative perspectives prior to arriving at a conclusion.

\subsection{Openness to Technological Novelty}

Another dimension of mindfulness is openness to new information [14]. In relation to MAT, we introduce the dimension of openness to novelty. Those with pedestrian technology usage are likely to be unable to purposefully adapt their technology usage in situations that require agility. As individuals consider current technology usage and consider how the elements of a new technology application, feature, or usage-pattern compare and contrast, they are prepared to appreciate how an adaptation decision impacts to their situation.

\subsection{Technological Orientation in the Present}

Lastly, we turn to how orientation in the present moment relates to MAT. As individuals create distinctions, this helps situate individuals in their present circumstances $[14,16]$. Individuals can adapt in non-mindful ways (e.g., herding $[61,62]$ ), and may be unaware of how a technology adaptation decision fits into the "big picture". Orientation in the present implies that a person is intentionally being aware of their surroundings, and how a technology adaptation decision will impact both their immediate circumstances and long-term situation.

\section{Table 1. Dimensions of Mindful Adaptation of Technology}

\begin{tabular}{|c|c|c|}
\hline Dimension & Definition & COVID-19 Example \\
\hline $\begin{array}{l}\text { Alertness to } \\
\text { Technological } \\
\text { Distinction }\end{array}$ & $\begin{array}{l}\text { The degree to which a person recognizes } \\
\text { how the occurrence of an event requires } \\
\text { technology usage that is different than } \\
\text { usage before or after that event. }\end{array}$ & $\begin{array}{l}\text { As in-person gatherings are prohibited, an } \\
\text { individual subscribes to a web- } \\
\text { conferencing software for a limited time } \\
\text { frame with the intention of discontinuing } \\
\text { the service once in-person gatherings } \\
\text { renew. }\end{array}$ \\
\hline $\begin{array}{c}\text { Awareness of Multiple } \\
\text { Technological } \\
\text { Perspectives }\end{array}$ & $\begin{array}{l}\text { The degree to which a person is aware of } \\
\text { multiple technology adaptation routes and } \\
\text { their varying advantages and } \\
\text { disadvantages. }\end{array}$ & $\begin{array}{l}\text { A self-employed person posts a question } \\
\text { on an online forum to solicit (and later } \\
\text { consider) advice on with how forum } \\
\text { members would adapt technology usage. }\end{array}$ \\
\hline $\begin{array}{c}\text { Openness to } \\
\text { Technological Novelty }\end{array}$ & $\begin{array}{l}\text { The degree to which a person considers } \\
\text { various ways in which technology and } \\
\text { technology features can be used to } \\
\text { respond to an event. }\end{array}$ & $\begin{array}{l}\text { A mother reviews currently owned and } \\
\text { not-yet-purchased applications to see how } \\
\text { their individual features can help occupy } \\
\text { her children while she works remotely. }\end{array}$ \\
\hline $\begin{array}{l}\text { Technological } \\
\text { Orientation in the } \\
\text { Present }\end{array}$ & $\begin{array}{l}\text { The degree to which a person refrains } \\
\text { from becoming consumed with an event } \\
\text { and instead focuses on how various } \\
\text { technology adaptation options can lead to } \\
\text { both specific and general solutions. }\end{array}$ & $\begin{array}{l}\text { An employee who suddenly is required to } \\
\text { work from home considers the many } \\
\text { ways in which technology can improve } \\
\text { his/her task efficiency for both work and } \\
\text { non-work purposes. }\end{array}$ \\
\hline
\end{tabular}

Mindfulness requires effort. As Langer and Moldoveanu note, "mindfulness is not a cold cognitive process. When one is actively drawing novel distinctions, the whole individual is involved" [14:2].

\section{Research Model}

Jane is employed as a software developer working within New York city. In late January of 2020, she becomes aware of the COVID-19 pandemic, but doesn't think much of it. By mid-March, Jane's company announces that all employees will be required to work from home, and in addition, her 8-year old son's school cancels classroom attendance. Now, Jane can avoid a 2-hour commute. However, she must also learn to work from home with a young child who needs entertaining. Additionally, Jane is missing out on valuable in-person facetime with her boss; but she is grateful for the chance to eat lunch with her son on a regular basis. In response to her new circumstances, Jane-at the suggestion of a friend-reviews and then purchases several educational applications for her son. Additionally, Jane orients herself in the present during lunch times by disabling all phone notifications in order to take advantage of this formative time with her son. As the in-person restrictions continue for several weeks, she also schedules bi-weekly "lunch meetings" with her boss and coworkers via GoToMeeting to increase spontaneous collaboration during COVID-19. As Jane mindfully adapts her technology usage, she finds that the previous 
tension of family and work dynamic is loosened and her overall anxiety noticeable decreases.

The vignette above narrates our model in practice. As can be seen in Figure 1, we position MAT within existing coping and event systems theory to explore how individuals adapt their digital technology usage in the presence of ERCs.

Coping. As individuals become aware of an ERC, they engage in the primary appraisal process in which they evaluate whether the occurrence is an opportunity, threat, or a mixture of the two. In line with orthodox coping theorists [63], we include both the constructs of perceived opportunity and perceived threat. We delineate that an ERC can be primarily appraised as a threat or opportunity or as a combination of the two. In our example, Jane recognized that working from home as a result of COVID-19 was both a threat (e.g., decreased facetime with her boss) and an opportunity (e.g., eating lunch with her son). In reaction to some of the threats (opportunities), Jane was able to adapt her technology usage. While perceived opportunity and perceived threat are expected to vary in the strength of their relationship with MAT, we posit that in relation to ERCs, both will result in a direct effect with MAT.

Proposition 1: A high level of perceived opportunity will have a positive, direct effect on mindful adaptation of technology.

Proposition 2: A high level of perceived threat will have a positive, direct effect on mindful adaptation of technology.

As part of the secondary appraisal process, we only include perceived controllability (and omit perceived avoidance) as a mechanism. In regards to our omission of avoidance as a construct, ERCs "exceed [an entities] capacity to prevent" [10:113]; thus, to a certain extent, the role of avoidance as a mechanism is diluted. Perceived controllability refers to the process wherein individuals evaluate available coping resources and potential options to assess the amount of control they have to curb negative results or maximize benefits [64].We reinforce the concept that mindfulness requires effort, and a low level of perceived controllability is likely to be demotivating for actors. Indeed, a core tenant of mindfulness is an exploration of, openness to, and awareness of potential routes of action, which naturally implies some level of controllability. In our example, Jane had no real way of avoiding the reality of in-person restrictions, but she could still control certain elements of her environment (e.g., choosing to setup virtual lunches). We anticipate that in the presence of
ERCs, that a higher perception of control will positively moderate MAT behaviors. Put more formally:

Proposition 3: Perceived control will positively moderate the relationship between perceived opportunity (threat) and mindful adaptation of technology.

Event. One of the main advantages of incorporating event-related constructs in studying ERCs is the emphasis on the event and characteristics of that event. Models such as coping model of user adaptation [63] recognize the importance of an event in effecting user coping; however, the attributes of the event are unarticulated. One of the strengths of event system theory is the focus on spatial and temporal impacts of events. Event as a construct is not unidimensional, but rather a conglomerate of attributes (e.g., criticality, urgency, duration). This is an important distinction when studying ERCs where the event is overwhelmingly present. Thus, our model places event perception, which is composed of three attributescriticality, urgency, and duration-as informing the primary appraisal coping process. As an event unfolds, individuals will reengage in the primary appraisal process. In our vignette, Jane was aware of the ERC (COVID-19) but initially viewed it as only a minor threat or opportunity. However, the ERC increased in criticality and urgency, Jane reassessed the situation as both an authentic opportunity (e.g., no commute) and a threat (e.g., no in-person facetime with colleagues). Thus, perceived duration captures the variance observed from a temporal perspective. As perceived event urgency, duration, and criticality increase, the overall perceived intensity of the event is magnified. This will also have an indirect effect on MAT via the primary appraisal coping process. Thus, in relation to event attributes, we propose the following:

Proposition 4: Perceived event (a) criticality, (b) urgency, and (c) duration will have a positive, direct effect on the primary appraisal coping process.

In line with dual processing theory [65], we suspect that event-related constructs will not simply influence the primary appraisal coping process, but will also have a direct effect on MAT. Dual processing forwards the existence of two routes or systems [66]: the central and peripheral. We contend that event-related constructsvia the peripheral route-will also have a direct effect on MAT. Many adaptation behaviors occur independent of whether or not they are perceived as containing a high level of opportunity, threat or control. While some adaptation decisions may be conscientious and premeditated, ERCs are likely to spark reactions that 
bypass the coping mechanisms. This reasoning resonates with other theories, such as the elaboration likelihood model [67].

In addition, events are essentially complex and may have effects that are across space, time and organizational hierarchy [6]. Therefore, factors other than coping-related constructs such as organizational norm, peer pressure, and pro-social beliefs may also play a role in how people interpret an event and thus respond with MAT. Thus, we propose that:

Proposition 5: Perceived event (a) criticality, (b) urgency, and (c) duration will have a positive, direct effect on mindful adaptation of technology.

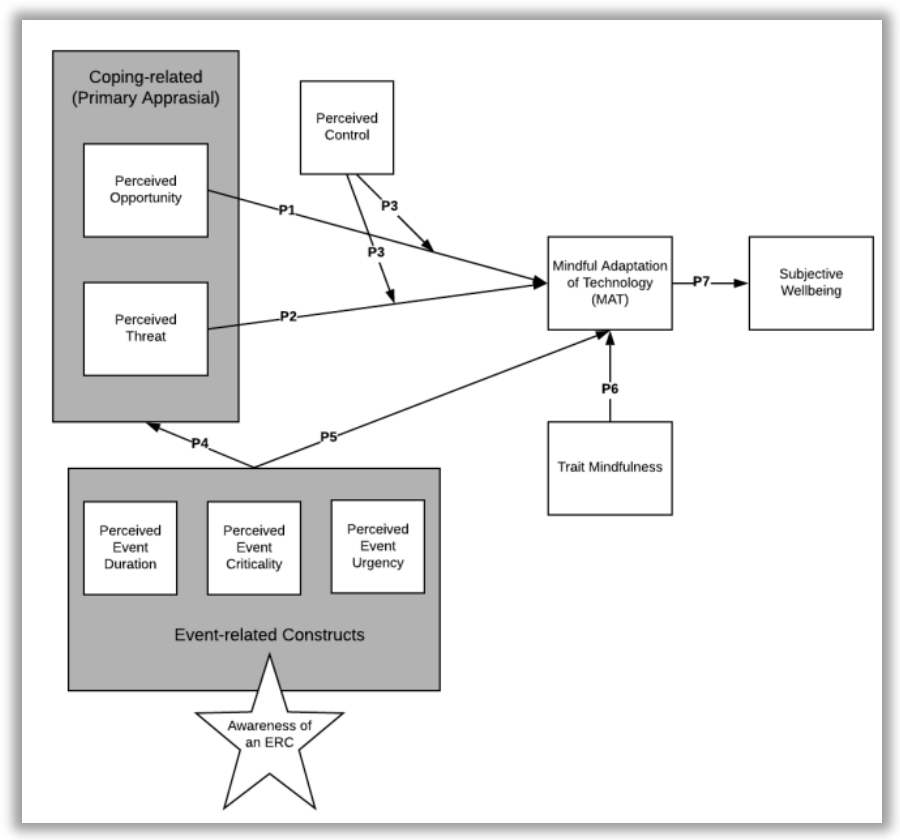

Figure 1. Mindful Adaptation of Technology (MAT) Framework

General Mindfulness. We recognize that mindfulness is not singularly a state variable, but also a trait that many individuals cultivate [68]. Previous research maintains that the personality trait of mindfulness is related to flexible response to stimuli and increased subjective wellbeing [69]. Through actions such as prayer, meditating, yoga, journaling, etc. individuals harness an ability to call upon mindfulness practices as they encounter the challenges of daily life. The effort required for such discipline is intended to bear fruit in the presence of ERCs (e.g., increased reliance, perspective). For example, an individual who has routinely practiced being present in the moment (a common meditation practice [70]), will likely be able to more easily orient their technology adaptation in the present circumstances. Thus, we anticipate that the trait of mindfulness will influence MAT. We thus propose:

Proposition 6: Mindful adaptation of technology will be positively informed by trait mindfulness.

Subjective Wellbeing. Lastly, we emphasize that meaningful outcome constructs, such as subjective wellbeing, should be studied in reference to ERCs.
Individuals feel an abundance of subjective wellbeing "when they feel many pleasant and few unpleasant emotions, when they are engaged in interesting activities, when they experience many pleasures and few pains, and when they are satisfied with their lives" [71:34]. Previous research has shown how technology adaptation can affect outcomes in one aspect of life, such as job-related outcomes [18]. We applaud this stream of research; however, we cannot help but recognize that - in some instances-adaptation of technology can have a real and meaningful impact on subjective wellbeing measures from happiness in our personal relationships to purpose in our professional duties. This is highlighted in the presence of ERCs where the event is likely to cause "an extensive and intolerable magnitude of physical, psychological, or material consequences" [10:113-115]. Robust MAT can combat these negative consequences. Thus, we postulate the following:

Proposition 7: Robust mindful adaptation of technology will have a positive, meaningful effect on subjective wellbeing outcomes. 


\section{Discussion}

\subsection{Research Contributions and Implications}

Our propositions forward research in several ways. First, we marry two rich and developed research streams by introducing a framework that explores ERCs in partnership with a technology-framed coping model. This union provides grounds whereupon future researchers may explore individual technology coping efforts in dramatic atmospheres. Second, we enrich technology adaptation research by reemphasizing the importance of events. De Guinea and Webster define discrepant IT events as "unexpected negative events that occur when there is a difference between that is expected and what is taking place and they entail a problem, a misunderstanding, or a difficulty with the IT being employed" [72:1168]. In this regard, much of existing IS coping literatures focuses on how an ITrelated occurrence acts as an event. The intensity of ITrelated events can be seen as ordinal; however, the range of intensity is dwarfed when ERCs become the focal event. We contend that ERCs have spillover effects, which can create IT-related events (e.g., hurricane wiping out multiple datacenters, large protest restricting cellphone bandwidth). Thus, event system theory allows for a more thorough appreciation of the multifaceted nature of the event construct.

Third, we conceptualize a new construct-MATand develop an instrument for measuring it. As a review, MAT applies well-established mindfulness constructs [13-16] to understand the adaptation of technology. In this way, MAT not only illuminates coping with ERCs, but also has utility for understanding coping behavior in reaction to more specific events (e.g., technostress, IT security). Finally, we give rise to the importance of technology adaptation outcomes by including subjective wellbeing factors. Earlier we emphasized how ERCs breaches multiple aspects of one's life. By replacing job-related outcomes with subjective wellbeing outcomes, we showcase how this model can have a meaningful impact in one's life.

Both practitioners and individuals can benefit from the arguments contained herein. To those who are engulfed in an ERC (such as COVID-19) adapting digital technology use is postulated to positively influence one's subjective wellbeing. Adapting digital technology can imply any change to how digital technology is used, and we would encourage individuals and organizations to think creatively about how they use digital technology and how that impacts elements of work and life.

Lastly, we recognize that our proposed framework is in an embryonic stage, and we anticipate that further conceptual and empirical efforts will give light to boundaries and limitations of our model. For example, this model should be adopted to more appropriately capture variation attributable to context (e.g., developing versus developed countries). Depending on prior theoretical work, scholars may consider the role of certain variables (e.g., gender, age) or they may wish to control for the variance introduced by these variables.

\subsection{Conclusion}

The effects of COVID-19 are likely to continue for years to come, and one of the benefits of studying ERCs is the voluminous amount of archival data at hand [10]. By accessing the rich data that is publicly available regarding ERCs, we invite future research to consider operationalizing the constructs we have set forth to understand the ways in which individuals mindfully adapt their technology usage.

\section{Funding}

This research is based upon work supported by the National Science Foundation under Grant No. 2027332 .

\section{References}

[1] "zoom - Explore - Google Trends", https://trends.google.com/trends/explore?date=today $\mathrm{y} \& \mathrm{geo}=\mathrm{US} \& \mathrm{q}=\mathrm{zoom}$

[2] Fox, M., "Zoom jumps $11 \%$ after company announces it added 100 million new users in 3 weeks (ZM) | Markets Insider", Business $\quad$ Insider, 2020. https://markets.businessinsider.com/news/stocks/zoom-stockprice-jumps-after-company-added-millions-userscoronavirus-2020-4-1029124065

[3] "COVID-19: The Unexpected Catalyst for Tech Adoption Nielsen", 2020.

https://www.nielsen.com/us/en/insights/article/2020/covid19-the-unexpected-catalyst-for-tech-adoption/

[4] King, S., "Why COVID-19 Is Accelerating The Adoption Of AI And Research Tech", Forbes.com, 2020. https://www.forbes.com/sites/steveking/2020/05/11/whycovid-19-is-accelerating-the-adoption-of-ai-and-researchtech/\#40b33fbf2140

[5] Lee, T.W., T.R. Mitchell, B.C. Holtom, L.S. McDaneil, and J.W. Hill, "The Unfolding Model of Voluntary Turnover: A Replication and Extension", Academy of Management Journal 42(4), pp. 450-462, 1999.

[6] Morgeson, F.P., T.R. Mitchell, and D. Liu, "Event system theory: An event-oriented approach to the organizational sciences", Academy of Management Review 40(4), pp. 515$537,2015$.

[7] Lycett, A., “Breaking Germany's Enigma Code”, 2011. http://www.bbc.co.uk/history/worldwars/wwtwo/enigma_01. shtml 
[8] Harford, T., "The Cold War spy technology which we all use", 2019. https://www.bbc.com/news/business-48859331

[9] LaFree, G., and L. Dugan, "Introducing the global terrorism database", Terrorism and Political Violence 19(2), pp. 181-204, 2007.

[10] Hällgren, M., L. Rouleau, and M. De Rond, "A matter of life or death: How extreme context research matters for management and organization studies", Academy of Management Annals 12(1), pp. 111-153, 2018.

[11] Christianson, M.K., M.T. Farkas, K.M. Sutcliffe, and K.E. Weick, "Learning through rare events: Significant interruptions at the Baltimore \& Ohio Railroad Museum", Organization Science 20(5), pp. 846-860, 2009.

[12] Thatcher, J.B., R.T. Wright, H. Sun, T.J. Zagenczyk, and R. Klein, "Mindfulness in information technology use: Definitions, distinctions, and a new measure", MIS Quarterly 42(3), pp. 831-847, 2018.

[13] Sun, H., Y. Fang, and H.M. Zou, "Choosing a fit technology: Understanding mindfulness in technology adoption and continuance", Journal of the Association for Information Systems 17(6), pp. 377-412, 2016.

[14] Langer, E.J., and M. Moldoveanu, "The construct of mindfulness", Journal of Social Issues 56(1), 2000, pp. 1-9.

[15] Langer, E.J., "Minding Matters: The Consequences of Mindlessness-Mindfulness", Advances in Experimental Social Psychology 22(C), pp. 137-173, 1989.

[16] Langer, E., Mindfulness. Reading, MA, US, 1989.

[17] Morgeson, F.P., and D.S. DeRue, "Event criticality, urgency, and duration: Understanding how events disrupt teams and influence team leader intervention", Leadership Quarterly 17(3), pp. 271-287, 2006.

[18] Weinert, C., "Coping with discrepant information technology events: A literature review", 26th European Conference on Information Systems: Beyond Digitization Facets of Socio-Technical Change, ECIS 2018, 2018.

[19] "EU referendum - Google Trends", https://trends.google.com/trends/story/GB_cu_EoBj9FIBAA Aj9M_en

[20] Katz, D., and R.L. Kahn, The social psychology of organizations, Wiley, New York, 1978.

[21] Berrien, F.K., "Homeostasis theory of groups: Implications for leadership", In Leadership and interpersonal behavior, pp. 82-99, 1961.

[22] Lu, S., W. Zhu, and J. Wei, "Assessing the impacts of tourism events on city development in China: a perspective of event system", Current Issues in Tourism 23(12), pp. 1528 $1541,2020$.

[23] Akkermans, J., J. Richardson, and M.L. Kraimer, "The Covid-19 crisis as a career shock: Implications for careers and vocational behavior", Journal of Vocational Behavior 119, 2020.

[24] Song, Z., L. He, and Y. Zhang, "How do entrepreneurs learn from critical events? A case study of critical event learning”, Chinese Management Studies 11(4), pp. 778-796, 2017.

[25] Owen, J., D.R. Marshall, and M.M. Novicevic, "Event System Theory of Instrumental Leadership: The Case of General Nathanael Greene", The Journal of Applied Management and Entrepreneurship 20(3), pp. 8-30, 2015.

[26] Rauthmann, J.F., R.A. Sherman, and D.C. Funder, "Principles of Situation Research: Towards a Better
Understanding of Psychological Situations", European Journal of Personality 29(3), pp. 363-381, 2015.

[27] Vaara, E., "Post-acquisition integration as sensemaking: Glimpses of ambiguity, confusion, hypocrisy, and politicization", Journal of Management Studies 40(4), pp. 859-894, 2003.

[28] Brown, G.W., F. Sklair, T.O. Harris, and J.L.T. Birley, "Life-events and psychiatric disorders Part 1: Some methodological issues", Psychological Medicine 3(1), pp. 7487, 1973.

[29] Weick, K.E., "Reflections on enacted sensemaking in the bhopal disaster", Journal of Management Studies 47(3), pp. 537-550, 2010.

[30] Barton, M.A., and K.M. Sutcliffe, "Overcoming dysfunctional momentum: Organizational safety as a social achievement", Human Relations 62(9), 2009, pp. 1327-1356. [31] Powley, E.H., "Reclaiming resilience and safety: Resilience activation in the critical period of crisis", Human Relations 62(9), pp. 1289-1326, 2009.

[32] Boudes, T., and H. Laroche, "Taking off the heat: Narrative sensemaking in post-crisis inquiry reports", Organization Studies 30(4), pp. 377-396, 2009.

[33] Clegg, S., M.P. e Cunha, and A. Rego, "The Theory and Practice of Utopia in a Total Institution: The Pineapple Panopticon", Organization Studies 33(12), pp. 1735-1757, 2012.

[34] Gersick, C.J.G., "Time and Transition in Work Teams: Toward a New Model of Group Development", Academy of Management Journal 31(1), pp. 9-41, 1988.

[35] Hoffman, E.L., and R.G. Lord, "A taxonomy of eventlevel dimensions: Implications for understanding leadership processes, behavior, and performance", Leadership Quarterly 24(4), pp. 558-571, 2013.

[36] Megerian, C., "Trump calls Americans 'warriors' in fight to open economy - Los Angeles Times", 2020. https://www.latimes.com/politics/story/2020-05-06/trumpamericans-warriors-fight-to-open-economy

[37] Lazarus, R.S., "Cognition and motivation in emotion", American Psychologist 46(4), pp. 352-367, 1991.

[38] Lazarus, R., and S. Folkman, Stress, appraisal, and coping, Springer publishing company, 1984.

[39] Bhattacherjee, A., C.J. Davis, A.J. Connolly, and N. Hikmet, "User response to mandatory IT use: a coping theory perspective", European Journal of Information Systems 27(4), pp. 395-414, 2018.

[40] Bala, H., and V. Venkatesh, "Adaptation to information technology: A holistic nomological network from implementation to job outcomes", Management Science 62(1), pp. 156-179, 2016.

[41] Wilson, J., Mindful America: Meditation and the mutual transformation of Buddhism and American culture., Oxford University Press, 2014.

[42] Geer, J.H., G.C. Davison, and R.I. Gatchel, "Reduction of stress in humans through nonveridical perceived control of aversive stimulation", Journal of Personality and Social Psychology 16(4), pp. 731-738, 1970.

[43] Park, K., An experimental study of theory-based team building intervention: A case of Korean work groups., Cambridge.

[44] Butler, B.S., and P.H. Gray, Reliability, Mindfulness, and Information Systems, 2006. 
[45] Fiol, C.M., and E.J. O’Connor, "Waking up! Mindfulness in the of bandwagons", Academy of Management Review 28(1), pp. 54-70, 2003.

[46] Goswami, S., H.H. Teo, and H.C. Chan, "Real options from RFID adoption: The role of institutions and managerial mindfulness", ICIS 2008 Proceedings - Twenty Ninth International Conference on Information Systems, 2008, pp. $1-1$.

[47] Levinthal, D., and C. Rerup, "Crossing an apparent chasm: Bridging mindful and less-mindful perspectives on organizational learning", Organization Science 17(4), pp. 502-513, 2006.

[48] Sternberg, R.J., "Images of mindfulness", Journal of Social Issues 56(1), pp. 11-26, 2000.

[49] Weick, K., K. Sutcliffe, and D. Obstfeld, "Organizing for high reliability: processes of collective mindfulness, Research in organizational behaviour", 1999.

[50] Thatcher, J.B., R.T. Wright, H. Sun, T.J. Zagenczyk, and R. Klein, "Mindfulness in information technology use: Definitions, distinctions, and a new measure", MIS Quarterly 42(3), pp. 831-847, 2018.

[51] Dernbecher, S., and R. Beck, "The concept of mindfulness in information systems research: A multidimensional analysis", European Journal of Information Systems 26, pp. 121-142, 2017.

[52] Salovaara, A., K. Lyytinen, and E. Penttinen, "High reliability in digital organizing: Mindlessness, the frame problem, and digital operations", MIS Quarterly 43(2), pp. 555-578, 2019.

[53] Addas, S., and A. Pinsonneault, "E-mail interruptions and individual performance: Is there a silver lining?", MIS Quarterly 42(2), pp. 381-405, 2018.

[54] Curtis, A.M., A.R. Dennis, and K.O. McNamara, "From monologue to dialogue: Performative objects to promote collective mindfulness in computer-mediated team discussions", MIS Quarterly 41(2), pp. 559-581, 2017.

[55] Fichman, R., "Going Beyond the Dominant Paradigm for Information Technology Innovation Research: Emerging Concepts and Methods", Journal of the Association for Information Systems 5(8), pp. 314-355, 2004.

[56] Swanson, E.B., and N.C. Ramiller, "Innovating mindfully with information technology MIS Quarterly 28, 553-583, 2004.

[57] Sun, H., and Y. Fang, "Toward a model of mindfulness in technology acceptance", ICIS 2010 Proceedings - Thirty First International Conference on Information Systems, (2010).

[58] Sun, H., "Understanding user revisions when using information system features: Adaptive system use and triggers”, MIS Quarterly 36(2), pp. 453-478, 2012.
[59] Langer, E., J. Joss, M. Howell, and M. Hatem, "Conditional Teaching and Mindful Learning the Role of Uncertainty in Education”, Creativity Research Journal 2(3), pp. 139-150, 1989.

[60] Dane, E., "Paying attention to mindfulness and its effects on task performance in the workplace", Journal of Management 37(4), pp. 997-1018, 2011.

[61] Sun, H., "A longitudinal study of herd behavior in the adoption and continued use of technology", MIS Quarterly 37(4), pp. 1013-1041, 2013.

[62] Zou, H., H. Sun, and Y. Fang, "Understanding postAdoption regret from the perspectives of herding and mindfulness", 2015 International Conference on Information Systems: Exploring the Information Frontier, ICIS 2015, (2015).

[63] Beaudry, A., and A. Pinsonneault, "Understanding user responses to information technology: A coping model of user adaptation", MIS Quarterly 29, pp. 493-524, 2005.

[64] Major, B., C. Richards, C. Cozzarelli, M.L. Cooper, and J. Zubek, "Personal Resilience, Cognitive Appraisals, and Coping: An Integrative Model of Adjustment to Abortion", Journal of Personality and Social Psychology 74(3), pp. 735752, 1998.

[65] Chaiken, S., and T. Yaacov, Dual-process theories in social psychology, Guilford Press, 1999.

[66] Kahneman, D., Thinking, fast and slow, Farrar, Straus and Giroux, New York, 2011.

[67] Petty, R. E., \& Cacioppo, J.T., Communication and persuasion: Central and peripheral routes to attitude change, Springer Science \& Business Media, 2012.

[68] Brown, K.W., and R.M. Ryan, "The Benefits of Being Present: Mindfulness and Its Role in Psychological WellBeing", Journal of Personality and Social Psychology 84, pp. 822-848, 2003.

[69] Sun, S., C. Hu, J. Pan, C. Liu, and M. Huang, "Trait mindfulness is associated with the self-similarity of heart rate variability”, Frontiers in Psychology 10(FEB), 2019.

[70] Brahmavamso, A., The Basic Method of Meditation, 2003.

[71] Diener, E., "Subjective well-being: The science of happiness and a proposal for a national index", American Psychologist 55(1), pp. 34-43, 2000.

[72] De Guinea, A.O., and J. Webster, "An investigation of information systems use patterns: Technological events as triggers, the effect of time, and consequences for performance", MIS Quarterly 37(4), pp. 1165-1188, 2013. 